\title{
A transcriptomic computational analysis of mastic oil-treated Lewis lung carcinomas reveals molecular mechanisms targeting tumor cell growth and survival
}

\author{
Panagiotis Moulos $^{\dagger 1}$, Olga Papadodima ${ }^{\dagger 1}$, Aristotelis Chatziioannou ${ }^{1}$, \\ Heleni Loutrari*2, Charis Roussos ${ }^{2}$ and Fragiskos N Kolisis*1
}

\begin{abstract}
Address: ${ }^{1}$ Metabolic Engineering and Bioinformatics Group, Institute of Biological Research and Biotechnology, National Hellenic Research Foundation, 48 Vasileos Constantinou ave. 11635, Athens, Greece and 2"G.P. Livanos and M. Simou Laboratories", Evangelismos Hospital, Department of Critical Care and Pulmonary Services, School of Medicine, University of Athens, 2 Ploutarchou st., 10676, Athens, Greece

Email: Panagiotis Moulos - pmoulos@eie.gr; Olga Papadodima - opapadod@eie.gr; Aristotelis Chatziioannou - achatzi@eie.gr;

Heleni Loutrari* - elloutrar@med.uoa.gr; Charis Roussos - croussos@med.uoa.gr; Fragiskos N Kolisis* - kolisis@eie.gr

* Corresponding authors †Equal contributors
\end{abstract}

Published: 15 December 2009

BMC Medical Genomics 2009, 2:68 doi:10.1 186/1755-8794-2-68
Received: 4 June 2009

Accepted: I5 December 2009

This article is available from: http://www.biomedcentral.com/I755-8794/2/68

(C) 2009 Moulos et al; licensee BioMed Central Ltd.

This is an Open Access article distributed under the terms of the Creative Commons Attribution License (http://creativecommons.org/licenses/by/2.0), which permits unrestricted use, distribution, and reproduction in any medium, provided the original work is properly cited.

\begin{abstract}
Background: Mastic oil from Pistacia lentiscus variation chia, a blend of bioactive terpenes with recognized medicinal properties, has been recently shown to exert anti-tumor growth activity through inhibition of cancer cell proliferation, survival, angiogenesis and inflammatory response. However, no studies have addressed its mechanisms of action at genome-wide gene expression level.

Methods: To investigate molecular mechanisms triggered by mastic oil, Lewis Lung Carcinoma cells were treated with mastic oil or DMSO and RNA was collected at five distinct time points (3-48 h). Microarray expression profiling was performed using Illumina mouse- $6 \mathrm{vl}$ beadchips, followed by computational analysis. For a number of selected genes, RT-PCR validation was performed in LLC cells as well as in three human cancer cell lines of different origin (A549, HCTI 16, K562). PTEN specific inhibition by a bisperovanadium compound was applied to validate its contribution to mastic oil-mediated anti-tumor growth effects.
\end{abstract}

Results: In this work we demonstrated that exposure of Lewis lung carcinomas to mastic oil caused a timedependent alteration in the expression of 925 genes. GO analysis associated expression profiles with several biological processes and functions. Among them, modifications on cell cycle/proliferation, survival and NF- $\kappa B$ cascade in conjunction with concomitant regulation of genes encoding for PTEN, E2F7, HMOXI (up-regulation) and NODI (down-regulation) indicated some important mechanistic links underlying the anti-proliferative, proapoptotic and anti-inflammatory effects of mastic oil. The expression profiles of Hmox I, Pten and E2f7 genes were similarly altered by mastic oil in the majority of test cancer cell lines. Inhibition of PTEN partially reversed mastic oil effects on tumor cell growth, indicating a multi-target mechanism of action. Finally, k-means clustering, organized the significant gene list in eight clusters demonstrating a similar expression profile. Promoter analysis in a representative cluster revealed shared putative cis-elements suggesting a common regulatory transcription mechanism.

Conclusions: Present results provide novel evidence on the molecular basis of tumor growth inhibition mediated by mastic oil and set a rational basis for application of genomics and bioinformatic methodologies in the screening of natural compounds with potential cancer chemopreventive activities. 


\section{Background}

Lung cancer is the leading cause of cancer deaths in the US among both men and women [1]. Nowadays the search for new chemopreventive and chemotherapeutic agents to treat malignancies, especially the most mortal types characterized by rapid metastasis and frequent resistance to current chemotherapy/radiotherapy regimens has recently increased and the interest is mainly focused on natural compounds with low toxicity [2]. A large body of pre-clinical, clinical and epidemiological studies support that many phytochemicals, i.e. bioactive compounds isolated from plants, can delay tumor progression and metastasis $[3,4]$. While most of the available evidence refers to isolated substances, recent data support that natural combinations of phytochemicals in extracts often possess enhanced reactivity due to their additive and/or synergistic interactions [5]. Plant essential oils containing a wide spectrum of compounds seem to be promising in this respect. Mastic oil, the essential oil of mastic gum, a natural resin obtained from Pistacia lentiscus variation chia has been extensively used in the Mediterranean and Middle Eastern countries as food/beverages flavouring additive and traditional medicine since antiquity without any reported toxicity. Chemical composition analysis of mastic oil revealed that it is a complex mixture of volatile compounds, mainly terpenes, with established beneficial biological properties [6,7]. Although these compounds have been shown to inhibit a variety of tumor-promoting cellular pathways in cancer cells, their precise mechanism(s) of action is still uncertain. It appears that plantderived terpenes act primarily as inhibitors of the mevalonate pathway which regulates the biosynthesis of specific isoprenoids that are indispensable to the post-translational modification of small GTPase $[8,9]$. Regarding the health beneficial properties of mastic oil, it has been proved to act as antimicrobial [6,7], anti-inflammatory [10] and anti-atherogenic [11] agent without substantial side effects in humans and animals $[10,12]$.

Furthermore, recent studies have revealed that mastic extracts can also exert anti-tumor growth activities against several cancer types (leukemia, prostate, colon, lung and melanoma cancer cells) through mechanisms involving inhibition of tumor cell proliferation and survival, restriction of angiogenesis and modulation of pro-tumor inflammatory response [13-17]. In addition, mastic oil treatment has been shown to target the expression and function of key signaling and transcription regulators implicated in malignant phenotype like Ras/RhoA

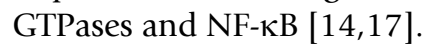

Despite the great number of reports analyzing the action mechanisms of plant derived compounds, studies focusing on their effects at the gene expression level are very limited. In this work, by combining sensitive high- throughput transcriptomic technology and bioinformatics on Lewis lung adenocarcinoma (LLC) cells, a susceptible to mastic oil cancer cell line [17], we were able to evaluate for the first time the differential expression of tumor genes in a genome-wide scale and identify target pathways modified in response to mastic oil treatment. Furthermore, by analyzing the expression of selected target genes in three additional human cancer cell lines we confirmed that the anti-tumor effects of mastic oil were more general. Our results might help to delineate the molecular basis of mastic oil chemopreventive/chemotherapeutic actions.

\section{Methods \\ Cell culture and treatment}

LLC and K562 cells were cultured in DMEM and RPMI 1640, respectively. Media were supplemented with $10 \%$ FCS, L-glutamine and antibiotics. HCT116 cells were maintained in DMEM supplemented with 10\% FCS, nonessential amino acids and antibiotics. A549 cells were maintained in F19-K supplemented with 10\% FCS and antibiotics. All cell lines were originally obtained from American Type Culture Collection, Manassas, VA and all media and supplements were from Gibco, Grand Island, NY. For RNA isolation, LLC cells were plated in 6-well plates at $2.3 \times 10^{5}$ cells/well, K562 in 24-well plates at $3 \times$ $10^{5}$ cells/well, HCT116 in 12 -well plates at $4 \times 10^{5}$ cells/ well and A549 were plated in 12-well plates at $1.5 \times 10^{5}$ cells/well. $24 \mathrm{~h}$ later cells were treated with mastic oil $(0.01 \%$ for LLC and $0.02 \% \mathrm{v} / \mathrm{v}$ for the other cell lines) or $0.1 \%$ DMSO vehicle for the indicated periods of time ( 3 to $48 \mathrm{~h})$.

\section{RNA isolation}

RNA was isolated with the Trizol Plus kit (Invitrogen, Carlsbad, CA, USA) according to the manufacturer instructions. The quantification and quality analysis of RNA was performed on a Bioanalyzer 2100 (Agilent, Santa Clara, California).

\section{Quantitative RT-PCR}

Reverse Transcription and Real-Time PCR was performed with the TaqMan RNA-to- $\mathrm{C}_{\mathrm{T}}$ 1-Step Kit. In the case of mouse genes TaqMan primers and probes were from Applied Biosystems, Foster City, California, while for human genes primers and probes were from Integrated DNA Technologies, Germany. The reactions were performed with $0.5 \mu \mathrm{g}$ of RNA as template, according to the manufacturer's instructions. Amplifications were performed on a 7500 Real-Time PCR System (Applied Biosystems Foster City, California) as follows: reverse transcription step at $48^{\circ} \mathrm{C}$ for $15 \mathrm{~min}$, followed by incubation at $95^{\circ} \mathrm{C}$ for $10 \mathrm{~min}$ and 40 cycles of $95^{\circ} \mathrm{C}$ for $15 \mathrm{~s}$ 
and $60^{\circ} \mathrm{C}$ for $1 \mathrm{~min}$. Gapdh gene was used as the reference gene for all normalizations. The sequence of primers and probes for mouse genes is as follows: Hmox1: Forward primer: 5'-GGTTGTAAGCATCCATGTTGACTGA-3', Reverse primer: 5'-ACAGAAATGTCTGGAAACGGATATCAA-3', Probe: 5'-CCAGTGCCATGGCCAC-3', Nod1: Forward primer: 5'-GAGCTGCACTCAGACTTCGA-3', Reverse primer: 5'-CCAGAGGGTGAGCCGG-3', Probe: 5'CCGCGTGCCGGATAG-3', Pten: Forward primer: 5'-AGATATTCTGACACCACTGACTCTGA-3', Reverse primer: 5'CAGACTTTTGTAATTTGTGAATGCTGATCTT-3', Probe: 5'TCCAGAGAATGAACCTTTTG-3', E2f7: Forward primer: 5'-CTCACACGGCGTCATCCA-3', Reverse primer: GCTCTGCCTTTACCATCGATACC-3', Probe: 5'-CCTGTTACGTGAGACATC-3', Gapdh: Forward primer: 5'GTGTCCGTCGTGGATCTGA-3', Reverse primer: 5'-GCTTCACCACCTTCTTGATGTCAT-3', Probe: 5'-CTTGGCAGGTTTCTCC-3'. The sequence of primers and probes for human genes is as follows: Hmox1: Forward primer: 5'CCCCAACGAAAAGCACAT-3', Reverse primer: 5'TGGAGGTTTGAGACAGCT-3', Probe: 5'-CCCCTCTGAAGTTTAGGCCATTGC-3', Nod1: Forward primer: 5'TCTTCСТCTACTTGCTCCAG-3', Reverse primer: 5'-GTTGACCACGACTTTGCT-3', Probe: 5'-CTTCTCCСCTTCCCTGCTCACT-3', Pten: Forward primer: 5'CAATGTTCAGTGGCGGAA-3', Reverse primer: 5'-TCGTGTGGGTCCTGAATT-3', Probe: 5'-TCACCTTTAGCTGGCAGACCACAA-3', E2f7: Forward primer: 5'TTCTACTCTTGGTGCTCTCC-3', Reverse primer: 5'AGCTGGGCTATTGATCCA-3', Probe: 5'-ACCTGTGAATTTCAGCTTGCCTGG-3', Gapdh: Forward primer: 5'-TGACCTGCCGTCTAGAAA-3', Reverse primer: 5'GTGTCGCTGTTGAAGTCA-3', Probe: 5'-AGTGTAGCCCAGGATGCCCTT-3'. Each reaction was analyzed in triplicates and data analysis was performed according to the $2^{-\Delta \Delta C_{T}}$ method.

\section{Cell growth assay}

K562 cells were plated in 96-well plates $\left(4 \times 10^{3}\right.$ cells/ well) and $24 \mathrm{~h}$ later were treated with fresh media containing mastic oil $(0.007 \% \mathrm{v} / \mathrm{v})$, potassium bisperoxo $(1,10-$ phenanthroline) oxovanadate $(\mathrm{bpV}(\mathrm{phen}))(1.0 \mu \mathrm{M})$ (Calbiochem, Merck, Darmstadt, Germany), mastic oil $(0.007 \% \mathrm{v} / \mathrm{v})$ together with $\mathrm{bpV}($ phen $)(0.5$ and $1.0 \mu \mathrm{M})$, or DMSO $(0.1 \%)$. The above concentrations of $\mathrm{bpV}$ (phen) were selected on the basis of earlier work showing that $\mathrm{bpV}$ (phen) is a specific inhibitor of PTEN at a concentration of $1 \mu \mathrm{M}$ or lower [18]. After $24 \mathrm{~h}$ of incubation, cell numbers were determined using CellTiter 96 $\mathrm{AQ}_{\text {ueous }}$ One Solution Cell Proliferation Assay (Promega, Madison, USA) according to manufacturers' instructions.

\section{Microarray hybridizations and data analysis}

Synthesis of cDNA and biotinylated cRNA was performed with the Illumina TotalPrep RNA Amplification Kit (Illumina, San Diego, California) using 500 ng of total RNA. Hybridization was performed in duplicates onto Illumina Mouse- 6 v1 Expression BeadChips according to manufacturer's instructions. The expression dataset, produced from the hybridization onto Illumina Mouse- 6 v1 Expression BeadChips, was corrected for background noise using Illumina's negative controls, representing an estimation of both image background and signals derived from nonspecific binding or cross-hybridizations. Data were normalized using the Rank Invariant normalization algorithm implemented on Illumina BeadStudio software, using all probes on the array for the extraction of the rank invariant set of genes. After normalization, data were filtered using Illumina's "detection score" which represents the probability that each probe's bead signal distribution does not overlap with the bead distribution of the negative control samples. A gene was considered "present" (P) if the detection was above 0.99. Genes scoring below 0.98 were considered as "absent" (A) while genes scoring between 0.98 and 0.99 as "marginally present" (M). Genes absent in all beadchips (20 in total) or present only in one beadchip were excluded from further analysis. Data were also normalized with Quantile normalization [19], with data filtering applied before normalization to alleviate it from the impact of systematic measurement errors to produce a second dataset of gene expression values.

To deal with the problem of negative signal values or values below 1 caused by the background subtraction step, all the remaining values below 1 were transformed to missing values. Subsequently, the experimental time points were divided into 10 subcategories ( 5 pairs of each time point's mastic oil treatment and its corresponding control), each consisting of duplicate expression values for each gene. For each subcategory, if the expression value for a gene was missing in both duplicate measurements, imputation was performed by replacing the missing value with 1 . If the expression value existed in one of the duplicates, then the existing value was used for the imputation of the other duplicate measurement according to the following strategy: expression values from the beadchip with the missing gene were divided in 20 physical intensity bins. The weighted mean of the 30 nearest neighbours (in terms of absolute distance) of the non-missing value from the bin where this value belonged to, was used to impute the missing one. After the imputation step, genes were further characterized as "weak" (W) if their expression value fell below the $5^{\text {th }}$ percentile of all expression values from the respective beadchip, "intermediate" (I) if the expression value was between the $5^{\text {th }}$ and $20^{\text {th }}$ percentile and "strong" (S) if it laid above the $20^{\text {th }}$ percentile. 


\section{Statistical analysis}

Differentially Expressed (DE) genes in at least one among all the experimental time points were identified by performing 1-way ANOVA on $\log _{2}$ transformed fold changes for each time-point. Fold change values were calculated for each gene as the ratio of the mastic oil to vehicle treatments. The resulting gene list was obtained by setting the p-value threshold to 0.05 and by removing genes that presented a fold change below $|0.2|$ (in $\log _{2}$ scale), in all time points. The described procedures were applied to both Rank Invariant and Quantile normalized data and the final gene list was obtained by the intersection of the lists, derived by the two normalizations. Noisy genes that remained after the initial filtering steps and characterized as WA, IA or WM in all time points, were removed. For the calculation of each gene's final p-value, an approach described before in [20] was used: as the dataset was normalized with two independent normalization methods, two different datasets having different value sets for each gene were produced. These normalized datasets were subjected to statistical testing, producing two different pvalue distributions. The $\mathrm{p}$-value for each gene equals the product of the two separate $\mathrm{p}$-values, produced by the statistical test for each normalization algorithm, due to their independent nature. Subsequently, the new p-value distribution was used to estimate the FDR levels, based on the method described in [21]. The final gene list corresponds to an FDR $<0.05$.

\section{Ontological analysis}

The final set of genes was analyzed according to the corresponding Gene Ontology Terms (GOTs) to these genes, for the identification of groups of genes referring to the same biological process or cellular biochemical pathway, using an algorithm presented in [20] currently assembled in a software package [22]. To further examine the significance of the extent of kinship for the resulting population of enriched GOTs, related to the categories 'Molecular Function' (MF) and 'Biological Process' (BP), a graph theoretic pairwise absolute distance metric ([23] and references therein), of the relevant GO tree was formulated and statistically tested:

$$
D_{c}=\frac{2}{n_{c}\left(n_{c}-1\right)} \sum_{i=1}^{n_{c}-1} \sum_{j=i+1}^{n_{c}} d_{G O T_{i}, G O T_{j}}^{U A G}
$$

where $n_{c}$ denotes the number of GOTs in either category (MF or $\mathrm{BP}$ ) and $d_{\mathrm{GOT}}^{\mathrm{UAG}, \mathrm{GOT}}$ denotes the absolute distance between nodes $i$ and $j$ in the GO Tree Undirected Acyclic Graph (UAG). $D_{c}$ represents the average of all the pairwise absolute distances between two GOTs, in the GO UAG calculated for both MFs and BPs. The GO Directed Acyclic
Graph (DAG) was retrieved using tools from MATLAB's 7.4 (R2007a) Bioinformatics Toolbox and converted to an Undirected Acyclic Graph (UAG) by transforming its adjacency matrix in order to measure absolute distances between DAG nodes. The aforementioned metric was applied for the case of MF and BP to both GOT populations (significant GO set and whole chip GO set).

The statistical validity of $D_{c}$, was assessed through resampling (1000 times) the same number of MF GOTs and BP GOTs as those in Table 1, and from the respective whole chip GO sets (background), resulting in two background (MFs and BPs) bootstrap distributions of $D_{c}$ 's. Statistical significance was assessed using the bootstrap p-value:

$$
\hat{p}_{c}=\frac{\#\left\{D_{c}^{\text {background }} \leq D_{c}^{\text {significant }}\right\}}{m},
$$

where $m$ is the number of resampling iterations. $\hat{p}_{c}$ is a modification of the estimation of the Achieved Significance Level for bootstrap, $A \hat{S} L_{\text {boot }}[24]$.

\section{Cluster analysis}

The final gene list was subjected to k-means clustering, using Pearson correlation distance to identify groups of genes presenting similar expression profiles. To determine the optimal number of clusters, k-means algorithm was executed with $\mathrm{k}$ ranging from 2 to 30 and the Gap statistic [25] was used to estimate the optimal number $\mathrm{k}$. This procedure was repeated 100 times so as to obtain a distribution of $\mathrm{k}_{\mathrm{i}}$ parameters, $\mathrm{i}=1 \ldots 100$. The optimal cluster number was the value with the highest appearance frequency in the $\mathrm{k}_{\mathrm{i}}$ distribution and was found to be 8 . All calculations apart from background correction and Rank Invariant normalization were performed using MATLAB 7.4 (R2007a).

\section{Promoter sequence retrieval and analysis}

We downloaded promoter sequences from -500 to +100 , relative to transcription start site, for each gene in cluster 2 for mouse and human from Cold Spring Harbor Laboratory Mammalian Promoter Database [26]. In the cases that alternative promoters were given for the same gene, we selected the one defined as the "best" [26]. For promoters that we could not detect in this database, we additionally searched the ElDorado database [27]. In the case of genes with multiple promoters supported by different transcripts, we selected the one corresponding to the Reference Sequence of NCBI. Out of 78 cluster 2 genes, we were able to obtain promoter sequences for 78 and 69 genes for mouse and human, respectively. To analyze each promoter set for common TF binding sites, we used the 
Table I: GO-analysis of gene expression alterations over time

\begin{tabular}{|c|c|c|c|}
\hline GO term annotation & Category & HT p-value & Enrichment \\
\hline kinase binding & MF & 0.0000013 & $4 / 11$ \\
\hline histone acetyltransferase activity & MF & 0.0000017 & $6 / 30$ \\
\hline glutathione transferase activity & MF & 0.0000064 & $6 / 36$ \\
\hline BMP signalling pathway & $\mathrm{BP}$ & 0.0000081 & $4 / 15$ \\
\hline Oxidoreductase activity & MF & 0.0000118 & $41 / 1019$ \\
\hline DNA replication initiation & $\mathrm{BP}$ & 0.0000295 & $4 / 19$ \\
\hline Acyltransferase activity & MF & 0.0000537 & $14 / 224$ \\
\hline magnesium ion binding & MF & 0.0000696 & $25 / 554$ \\
\hline negative regulation of cell proliferation & BP & 0.0002658 & $10 / 152$ \\
\hline cell cycle & $\mathrm{BP}$ & 0.0004519 & $27 / 694$ \\
\hline lipoprotein metabolic process & $\mathrm{BP}$ & 0,0004900 & $3 / 19$ \\
\hline transcription factor binding & MF & 0.0006180 & $9 / 142$ \\
\hline lipid transport & $\mathrm{BP}$ & $0.0007 \mid 25$ & $7 / 96$ \\
\hline glutathione metabolic process & $\mathrm{BP}$ & 0.0010504 & $3 / 23$ \\
\hline fatty acid metabolic process & $\mathrm{BP}$ & 0.0011307 & $7 / 103$ \\
\hline cytoskeletal protein binding & MF & 0.0012260 & $6 / 81$ \\
\hline protein amino acid dephosphorylation & $\mathrm{BP}$ & 0.0012779 & $|2 / 24|$ \\
\hline regulation of translational initiation & $\mathrm{BP}$ & 0.0016908 & $3 / 26$ \\
\hline positive regulation of $I-\kappa B$ kinase/NF- $\kappa B$ cascade & BP & 0.0019357 & $5 / 65$ \\
\hline Phosphoprotein phosphatase activity & MF & 0.0021059 & $12 / 255$ \\
\hline induction of apoptosis & $\mathrm{BP}$ & 0.0022511 & $8 / 141$ \\
\hline cell division & $\mathrm{BP}$ & 0.0023318 & $|4 / 32|$ \\
\hline positive regulation of transcription from RNA polymerase II promoter & $\mathrm{BP}$ & 0.0024536 & $11 / 229$ \\
\hline transcription regulator activity & MF & 0.0026217 & $14 / 325$ \\
\hline nucleotide metabolic process & $\mathrm{BP}$ & 0.0029513 & $4 / 49$ \\
\hline electron transport & $\mathrm{BP}$ & 0.0031794 & $23 / 645$ \\
\hline transcription coactivator activity & MF & 0.0032915 & $7 / 122$ \\
\hline ubiquitin-protein ligase activity & MF & 0.0034684 & $11 / 239$ \\
\hline negative regulation of transcription & $\mathrm{BP}$ & 0.0035622 & $8 / 151$ \\
\hline
\end{tabular}

The list of 925 significantly altered genes was submitted to GO analysis elucidating over-represented GO terms. HT p-value represents the hypergeometric test $p$-value score for each GO term. Enrichment represents the ratio of the number of times a GO term occurs in the significant gene list to the number of times this GO term exists in the list of the entire array. Selected categories for further analysis are shown in bold, italics.

MatInspector software [28]. The parameters used were as follows: Library version: Matrix Library 8.0, Matrix group: Vertebrates, Transcription Factor sites common to: $65 \%$ of input sequences, Core similarity: 0.75, Matrix similarity: Optimized and p-value cut-off was set at 0.01. Among the identified TF sites only those that were present in both species were considered.

\section{Results}

\section{Statistically significant differentiated genes}

To obtain the gene expression profile after treatment with mastic oil for five distinct time points $(3,6,12,24$ and 48 $\mathrm{h})$, LLC cells were cultured with $0.01 \% \mathrm{v} / \mathrm{v}$ mastic oil or $0.1 \%$ DMSO, mRNA was isolated from and subjected to high-throughput gene expression profiling using high density oligonucleotide Illumina beadchips to analyze gene expression changes. The complete dataset has been deposited in NCBI's Gene Expression Omnibus (GEO) and is accessible through GEO Series accession number GSE15287. Proper pre-processing was applied to the expression values of the dataset in order to address the issues of noise and missing values. Subsequently, the gen- erated dataset was normalized with two widely used microarray data normalization methods, as there exists no gold standard normalization method, with the scope to decrease the number of possible false positives during the statistical selection step.

Each normalized dataset was subjected to statistical testing separately and the results were combined to form the final differential expression gene lists. The two methods had $\sim 60 \%$ overlap. In order to identify significant alterations among all time points, 1-way ANOVA was applied to expression fold changes between expression in mastic oil and vehicle treated samples $(\mathrm{p}<0.05$, FDR $<0.05)$ coupled with further filtering on fold change $(>|0.2|$ in at least one time point in $\log _{2}$ scale). Statistical analysis coupled with fold change filtering yielded a list of 925 significantly differentiated genes (Additional file 1) which are depicted per time point using a volcano plot representation (Figure 1). In this figure, both statistical and empirical (fold change) thresholds are illustrated whereas red dots represent up-regulated genes and green dots represent down-regulated genes. Specifically, following the 

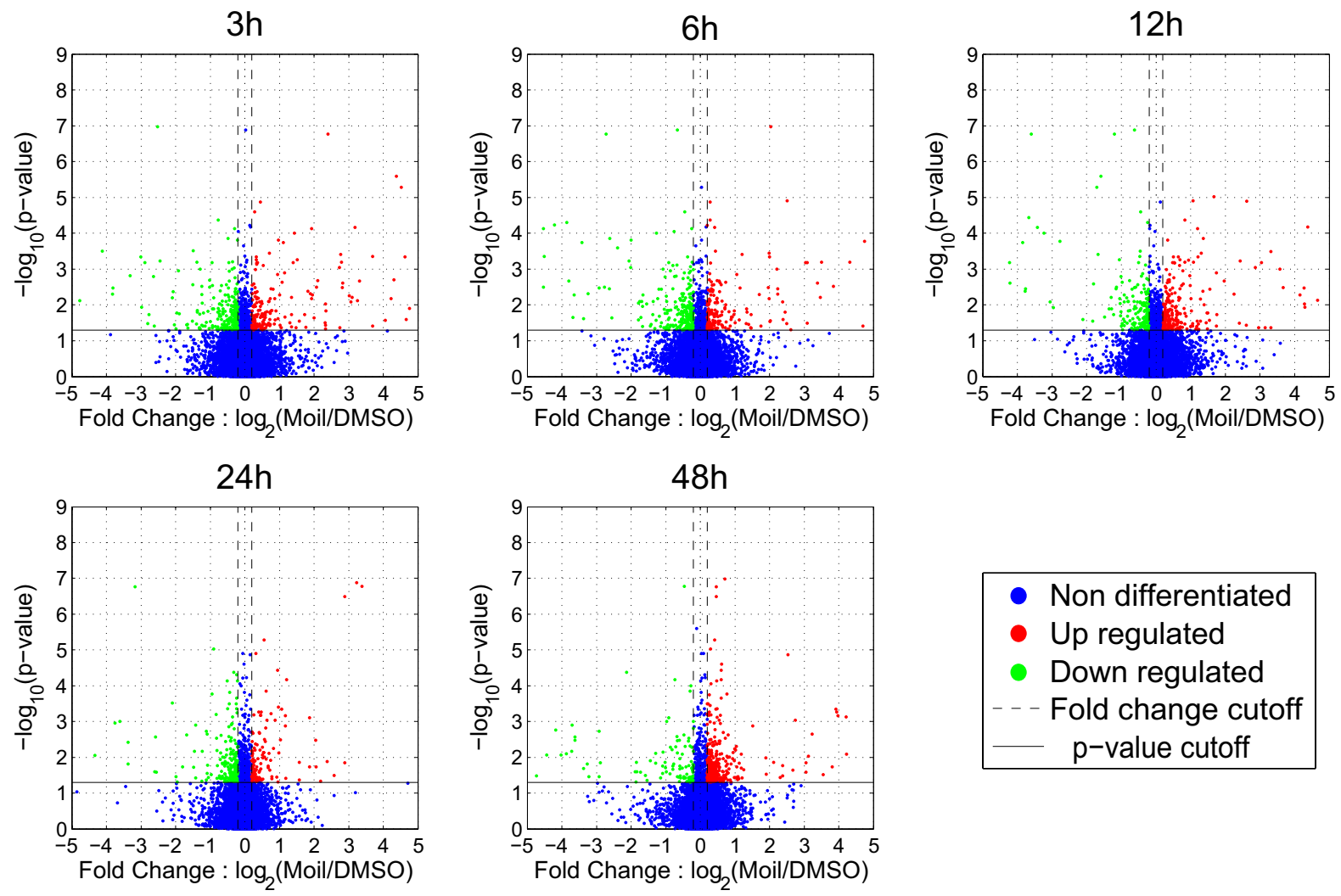

\begin{abstract}
Figure I
Volcano plots of the gene list as yielded by ANOVA. Each panel represents filtered and normalized data from each experimental time point $(3,6,12,24$ and $48 \mathrm{~h})$. The horizontal axes depict the fold change ratio between treatment with mastic oil and vehicle for each time point in $\log _{2}$ scale while the vertical axes represent statistical significance by depicting the $\log _{10}(p$-value). Larger values in the vertical axes represent larger statistical significance. Differentially expressed genes (fold change $>|0.2|$ in $\log _{2}$ scale, $P$-value $<0.05$, FDR $\left.<0.05\right)$ are shown in each panel where down-regulated genes are depicted by green dots and up-regulated genes by red dots. Non differentiated genes are shown as blue dots. Dashed lines indicate fold change thresholds and solid lines indicate the statistical significance ( $p$-value) threshold. The $p$-value threshold of 0.05 corresponds to the value 1.3 in the vertical axes using the aforementioned transformation.
\end{abstract}

aforementioned criteria, the numbers of differentiated genes for each of the 3,6,12, 24 and $48 \mathrm{~h}$ time points were $519,527,503,433$ and 550 respectively.

\section{GOT-based meta-analysis}

To gain evidence for possible altered biological processes, the list of genes resulting from ANOVA testing, was further subjected to ontological analysis based on Gene Ontology Terms (GOTs). Table 1 summarizes the over-represented GOTs with hypergeometric test $\mathrm{p}$-value $<0.01$. GO categories of "Molecular Function" (MF) and "Biological Process" (BP) are shown, while GO categories representing very general functions, like "catalytic activity" or "hydrolase activity", are excluded. In order to further assess the correlation of the qualified GOTs, with specific biological processes, which can be conceptually visualized as a cohesive net of connected GOTs, a resampling algorithm was applied, as described in Methods section. The results (bootstrap p-values $\mathrm{p}_{\mathrm{MF}}=0$ and $\mathrm{p}_{\mathrm{BP}}=0.001$ ) support strongly the validity of the over-represented GO terms in Table 1 network of connections. In this sense, the derived GOTs strongly support the reliability of the mild fold change expression thresholds adopted in this study for the derivation of the significant gene list.

From the GO categories presented in Table 1, emphasis was given in four categories, namely "negative regulation of cell proliferation", "cell cycle", "induction of apopto- 


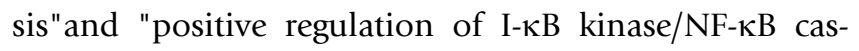
cade". Besides their established key role in cancer progression, the above categories were chosen on the basis of previous experimental evidence supporting that mastic oil inhibits LLC tumor growth in part through modulation of processes relevant to cell proliferation, apoptosis and inflammation [17]. Figure 2 presents the selected GO categories with the relevant genes and their fold change ratios. Each GO category is linked to the related genes with arrows starting from the GO categories. From the sets of genes belonging to these categories, only those presenting fold change above $|1|$ in $\log _{2}$ scale in at least one time point were retained. Noteworthy, Pten (phosphatase and tensin homolog deleted on chromosome ten), is involved in three of the four GO categories, while in addition, there is evidence supporting a functional cross-talk between PTEN and NF- $\mathrm{KB}$ signaling $[29,30]$. Therefore the observed modulation of Pten seemed to play a prominent role in mastic oil-mediated anti-tumor actions.

\section{$R T-P C R$ validation and correlation with microarray data}

The results of microarray data analysis were further validated by quantitative RT-PCR analysis. Figure 3A presents mastic oil-induced changes in the expression of four representative genes picked from the list presented in Figure 2, namely Pten, E2f7, Nod1 and Hmox1, in all time points as assessed by both microarray and RT-PCR methods.
Generally, there was a very good correlation in the overall profile of differential expression as well as in particular time points between the two methods.

Specifically, Pten shows constant expression at early time points (3-12 h) followed by significant up-regulation at $24 \mathrm{~h}$ and late modest down-regulation at $48 \mathrm{~h}$ as indicated by both microarray and RT-PCR data. Pten is the most elevated gene at $24 \mathrm{~h}$ and shows the highest agreement between microarray and RT-PCR data. Hmox1 is early induced at $3 \mathrm{~h}$ followed by almost constant expression in the remaining time points whereas RT-PCR and microarray data correlate very well. Nod1 is constantly repressed in all time points apart from $48 \mathrm{~h}$, presenting high accordance between RT-PCR and microarray expression. Finally, E2f7 is constantly expressed between 3-12 h and late upregulated at 24-48 $\mathrm{h}$ of mastic oil treatment. In the case of E2f7 although a discrepancy between microarray data and RT-PCR validation is observed at $24 \mathrm{~h}$ concerning the induction of the gene, yet the overall expression pattern remains similar across all time points.

Next, to investigate whether the aforementioned alterations are specific for mouse LLC cells or imply a more general response of cancer cells to mastic oil treatment, we examined by RT-PCR the expression profile of the above four selected genes in different types of human cancer cells. The results are presented in Figure 3B. Specifically,

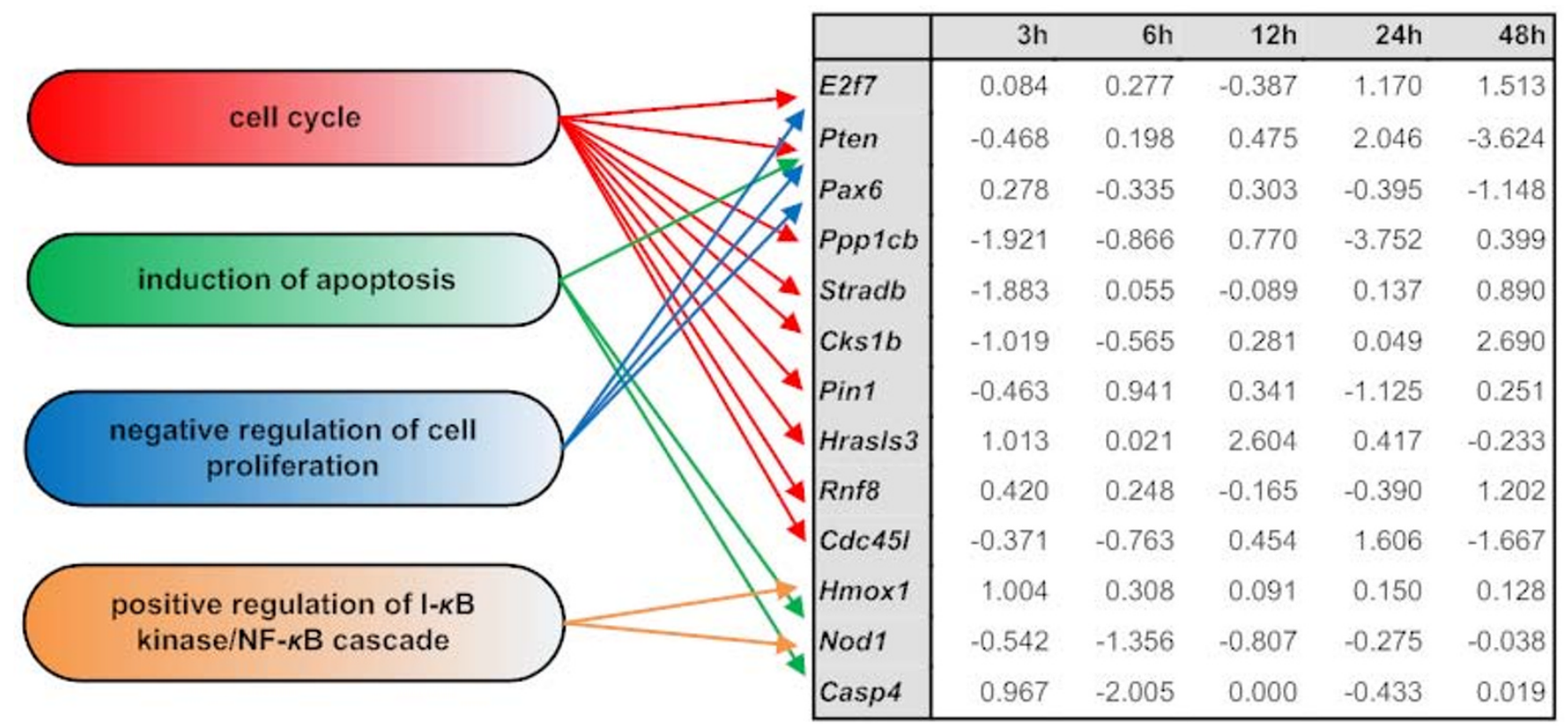

\section{Figure 2}

Selected GO categories and relevant genes. GO categories of interest and corresponding genes selected by fold change criteria as described in text. Values in 3,6, I2, 24 and $48 \mathrm{~h}$ depict fold changes between mastic oil treatment and its corresponding control in $\log _{2}$ scale for each time point. The arrows from each $\mathrm{GO}$ category on the left to the genes in the table on the right show which genes are functionally connected to each GO category within the GO hierarchical model. 
A.
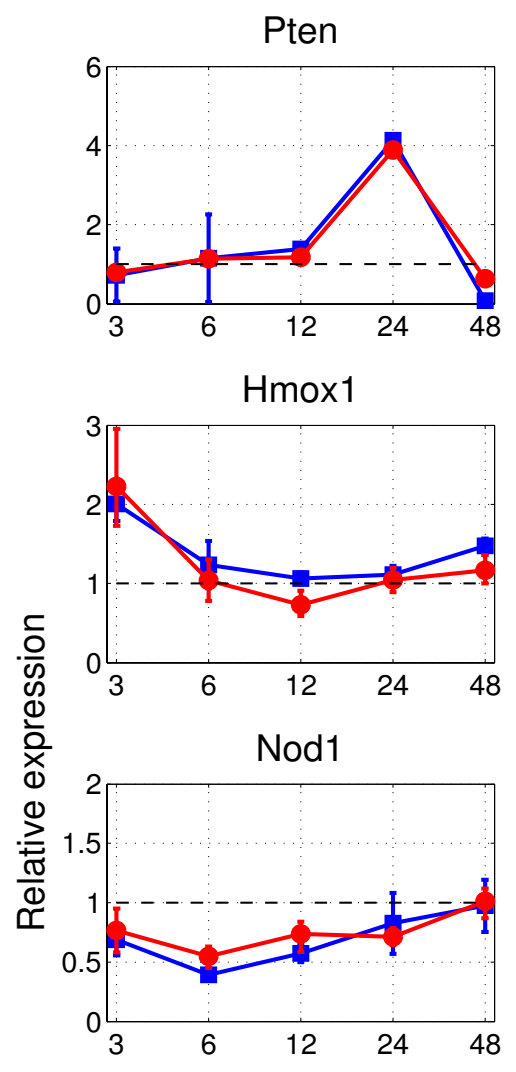

E2f7

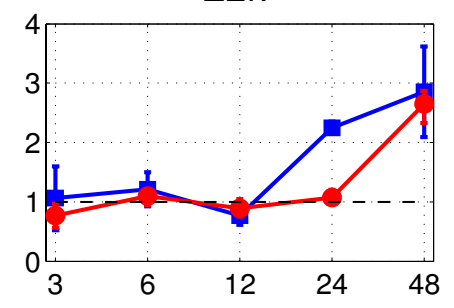

Time (hours)
B.
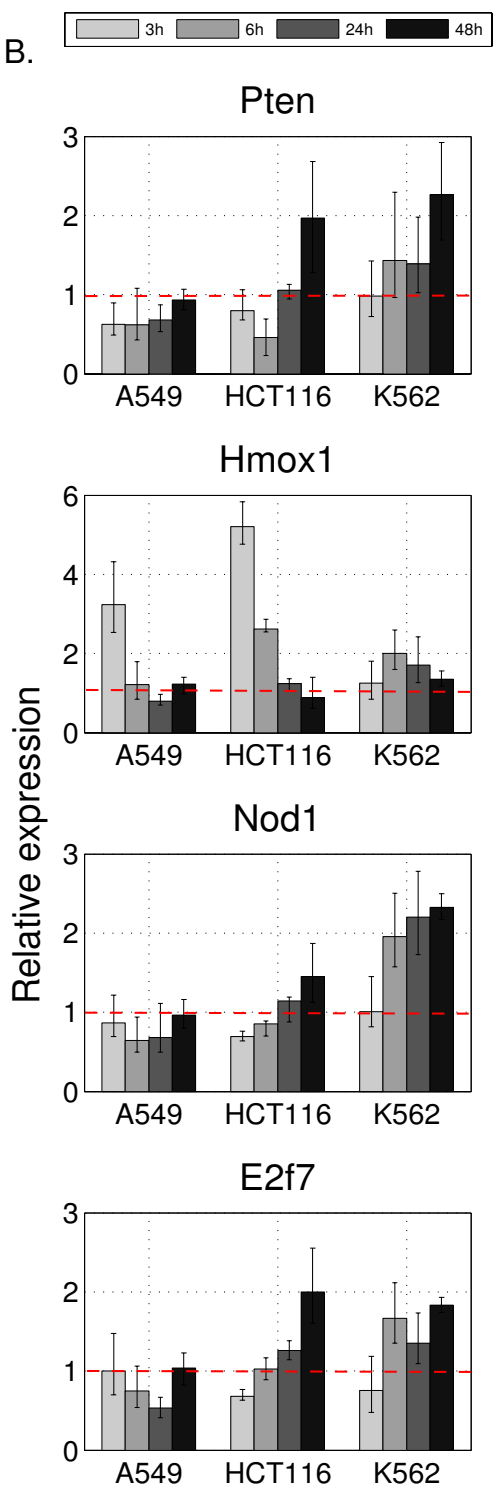

Cell line

Figure 3

Validation of microarray data by RT-PCR. Four selected genes (Pten, Hmox I, NodI and E2f7) were analyzed by quantitative RT-PCR for microarray data confirmation. Error bars on each time point represent minimum and maximum relative expression values for RT-PCR data and standard deviations for the microarray experiment data. The dashed horizontal line across the value $I$ on the vertical axes indicates that there is no difference in fold change ratios between treated and control cells. A. Expression levels measured by the two methods are shown for each time point. Specifically, for each of the depicted genes, the expression (in natural scale) of mastic oil treatment relative to its corresponding control, as derived from the microarray experiment and RT-PCR for each time point (3-48 h) is plotted and correlated. Overall, there is good correlation between microarray and RT-PCR validation data. B. The four selected genes from the analysis of microarray experiment were analyzed by quantitative RT-PCR in 3 cancer cell lines of human origin, namely A549, HCTII6 and K562. Expression levels were measured for 4 distinct time points. Each panel shows the expression of mastic oil treatment relative to its control for each time point and for each cell line. 
three different cell lines, namely lung adenocarcinoma (A549), colon carcinoma (HCT116) and erythromyeloblastoid leukaemia (K562) were used. A549 was selected as a human model of lung adenocarcinoma in analogy with LLC cells (lung adenocarcinoma in mice). HCT116 and K562 were used because of known susceptibility to mastic oil $[13,16]$. Gene expression was analyzed in four different time points (two early: 3 and $6 \mathrm{~h}$, two late: 24 and 48 h) of mastic oil treatment. In agreement with the observed induction of Pten in LLC cells, we observe an up-regulation in both $\mathrm{K} 562$ and HCT116 cells, with a major induction at $48 \mathrm{~h}$, but no response in A549 cells. Hmox 1 demonstrates an increased expression in all of the three cell lines, mainly at early time points, which is in agreement with its induction at $3 \mathrm{~h}$ in the case of LLC cells. Regarding Nod1, in contrast to its down-regulation in LLC cells, we observe an elevation of its expression in $\mathrm{K} 562$ cells that was more modest in HCT116 cells and no significant response in A549 cells. Finally, E2f7 displays an induced expression both in K562 and HCT116 cells, in line with its profile in LLC cells but it is not significantly modified in A549 cells.

PTEN mediates tumor cell growth inhibition by mastic oil Based on the reported role of PTEN as a key negative regulator of the PI3K-AKT survival pathway [31] and given its observed up-regulation by mastic oil in three different tumor cell lines, we investigated whether the inhibitory effects of mastic oil on tumor cell growth are mediated by PTEN. For this purpose, dividing K562 cells were treated for $24 \mathrm{~h}$ with $0.01 \%$ mastic oil in the presence or not of 0.5-1 $\mu \mathrm{M}$ bpV(phen), a specific PTEN inhibitor [18], and the number of viable cells was determined. Mastic oil induced a decrease in cell number (viable cells were $54.9 \%$ of control treatment), which was partially reversed in the presence of $\mathrm{bpV}$ (phen) in a concentration-dependent manner (Figure 4). Specifically, in the presence of 1 $\mu \mathrm{M}$ and $0.5 \mu \mathrm{M}$ of $\mathrm{bpV}$ (phen) the relevant cell number was $67.9 \%$ and $62.2 \%$ of control treatment, respectively.

\section{Dynamic clustering profile of gene expression data}

In order to identify groups of genes presenting similar expression profiles during the 3-48 h of mastic oil treatment and possibly comprising regulated "waves" of transcription, the list of 925 significantly differentiated genes was subjected to k-means clustering using Pearson correlation distance. Eight clusters containing genes with similar expression profiles were identified (Figure 5). Clusterbased GOT analysis connected regulated genes in each cluster to several functional categories where regulated genes are overrepresented. Due to the hierarchical structure of GO categories, the same gene can be linked to multiple GO terms.

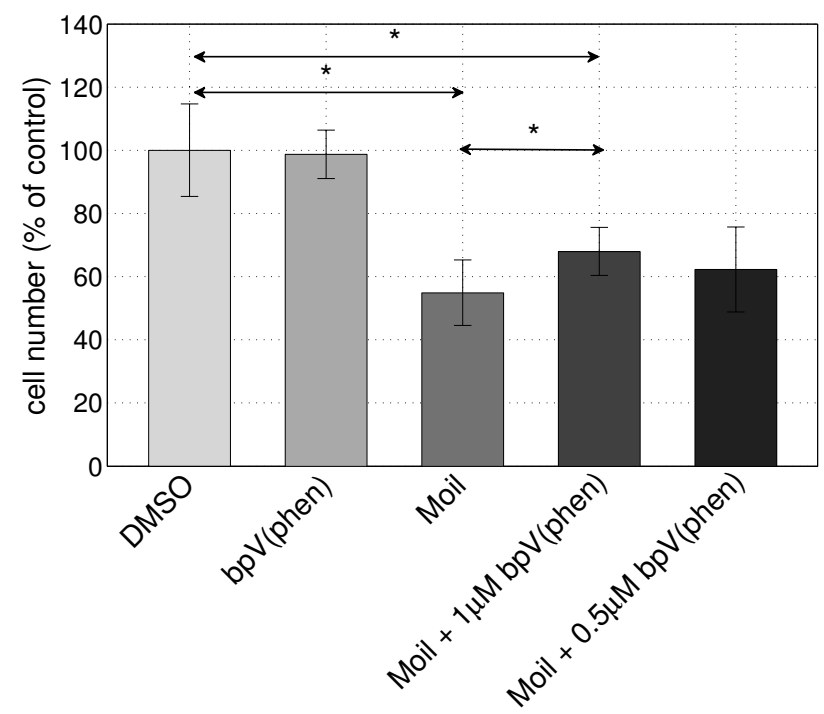

\section{Figure 4}

Inhibition of PTEN reverses mastic oil effect on $\mathrm{K562}$ cell growth. $\mathrm{K} 562$ cells were treated with mastic oil alone (Moil, $0.007 \% \mathrm{v} / \mathrm{v}$ ) or in the presence of PTEN inhibitor bpV(phen) $(0.5 \mu \mathrm{M}$ and I $\mu \mathrm{M}), \mathrm{bpV}$ (phen) alone (I $\mu \mathrm{M})$ or DMSO as control. Cell numbers were measured after $24 \mathrm{~h}$ and results are expressed as mean percentage of DMSO control $\pm S D$. The mean percentage of viable cells is significantly different between categories indicated by an asterisk as assessed by t-test $(p<0.05)$. The above statistics are derived from at least 3 independent experiments.

Cluster 1 contains genes among which a number showing early up-regulation at $6 \mathrm{~h}$ followed by down-regulation at $12 \mathrm{~h}$. Genes under cluster 1 are functionally connected to glutathione transferases activity as well as glutathione metabolism (Gstt1, Gstz1) which are down-regulated at 12 h. Glutathione comprises a well known antioxidant involved also in xenobiotic metabolism, the depletion of which has been reported to impair cell proliferation and cell growth and is an early event during apoptosis [32]. Cluster 2 contains genes, among which certain are constantly expressed at early time points and the majority of which manifests up-regulation in $24 \mathrm{~h}$ and late down-regulation at $48 \mathrm{~h}$. Functions represented by genes in cluster 2 include cholesterol metabolic process ( Hdlbp), negative regulation of cell proliferation (Pten, Cebpa) and fatty acid biosynthetic process (Ndufab1). Interestingly, Pten has been reported as a tumor-suppressor with role in cancer expansion and metastasis [33,34].

Cluster 3 depicts genes showing early down-regulation at $3 \mathrm{~h}$ followed by up-regulation at $6 \mathrm{~h}$ and then remaining mostly constant. Biological functions in cluster 3 include chemotaxis and chemokine activity $(\mathrm{Cxcl} 2)$ as well as regulation of transcription (Ncoa2, E2f2). On the other hand, 

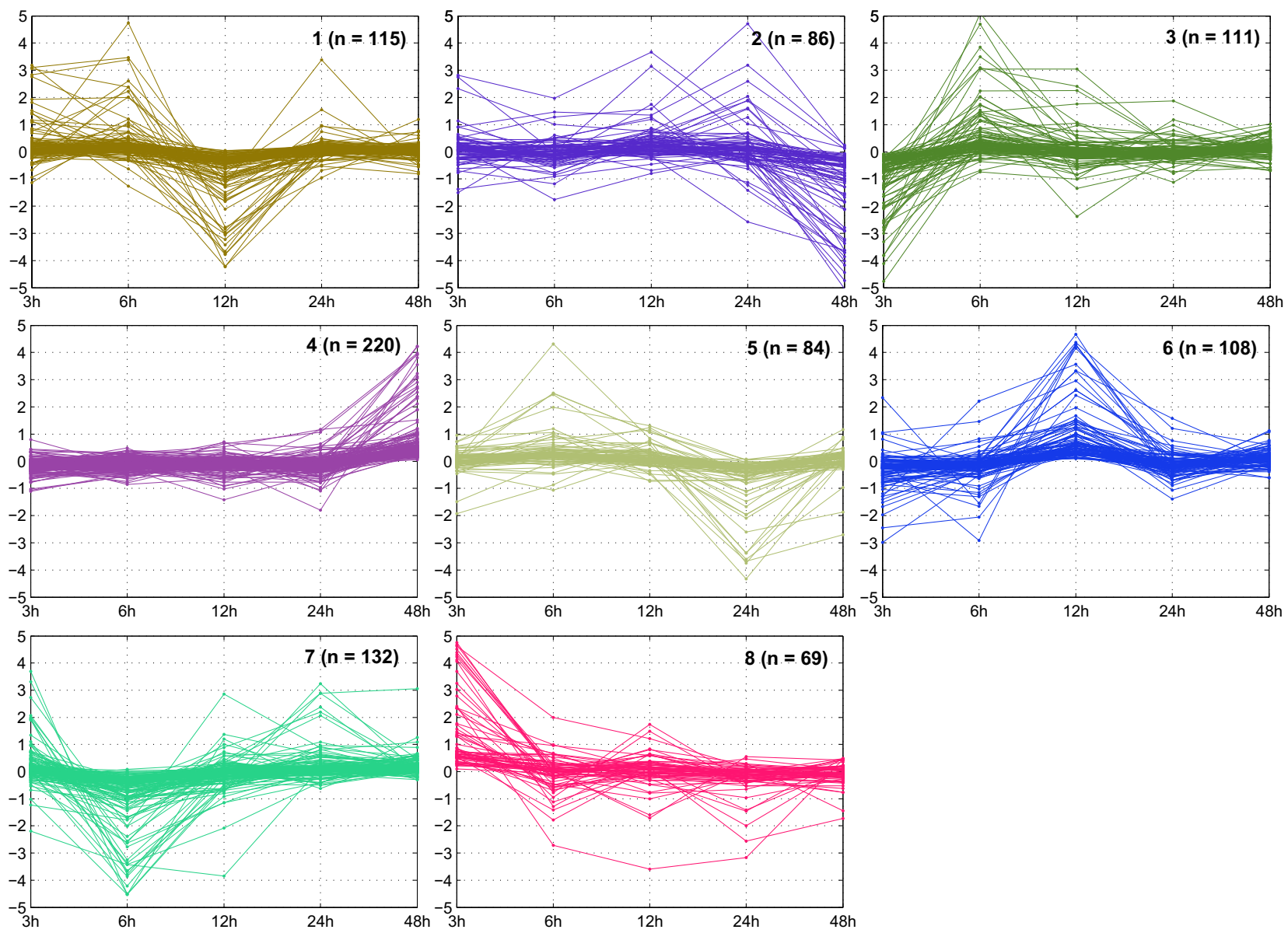

Figure 5

Clustering of gene expression profiles. Eight clusters of Illumina probe sets comprising similar expression profiles were identified by k-means clustering as described in methods. Each panel depicts one cluster of genes showing similar expression profile. The vertical axes depict fold changes in $\log _{2}$ scale between mastic oil treatment and its corresponding control for each time point, as derived from microarray data analysis. $n$ depicts the number of probe sets in each cluster.

cluster 4 includes genes showing down-regulation at $24 \mathrm{~h}$, followed by late induction at $48 \mathrm{~h}$. Cluster 4 is functionally connected to cell cycle (E2f7, Rnf8, Cks1b, Cdc45l), cell division (Cks1b, Mad1l1), cell cycle arrest (Bard1, Cdkn1a) and negative regulation of cell proliferation (E2f7, Cdkn1a). Cluster 5 contains genes which are mostly up-regulated at $6 \mathrm{~h}$ and down-regulated at $24 \mathrm{~h}$ and is functionally connected with G1/S transition of mitotic cell cycle (Camk2d) and cell death (Clu).

Cluster 6, mainly comprises genes showing early downregulation at $6 \mathrm{~h}$ followed by up-regulation at $12 \mathrm{~h}$. Biological functions in cluster 6 include negative regulation of transcription (Dedd2, Nr1h3), cell growth (Xrn2) and activation of MAPK activity (Map3k5). Cluster 7 includes genes, the regulation of which is early-repressed at $6 \mathrm{~h}$. A certain subgroup is up-regulated at $24 \mathrm{~h}$. Cluster 7 is func- tionally connected to GTPase activity (Gnaq, Rab5a), positive regulation of $\mathrm{I}-\kappa \mathrm{B}$ kinase/NF- $\mathrm{KB}$ cascade ( $P p p 5 c$, Nod1), skeletal development (Gnaq) and response to hypoxia $(U b q \ln 1)$. Nod1 is a known NF-кB mediated proinflammatory agent involved in pro-apoptotic and antiinflammatory signals [35]. Finally, cluster 8 groups together early up-regulated genes at $3 \mathrm{~h}$ and includes overrepresented functions related to cell migration $(\mathrm{N} c k 2)$, cell motility (Mospd2) and regulation of cell shape (Centd3). Generally, in all clusters the observed alterations in gene expression seem to be transient, as most genes exhibit altered expression for one or two time points and then their expression returns to control levels.

\section{Promoter analysis of genes in cluster 2}

In order to investigate whether there is a common regulatory transcriptional mechanism underlying the common 
expression profiles revealed by clustering, we performed a representative promoter analysis in genes of cluster 2 . This cluster contains 86 probe sets corresponding to 78 genes and includes Pten. Cluster 2 genes present a common expression pattern characterized by up-regulation in $24 \mathrm{~h}$ followed by down-regulation in $48 \mathrm{~h}$. In order to find common putative transcription factor (TF) binding sites in at least a subset of cluster 2 genes, proximal promoter sequences from both mouse and human genomes were extracted from available databases and analyzed as described in Methods. Only common TF binding sites among the two species were considered. Table 2 summarizes statistically significant TF motif families common in promoter sequences of cluster 2 genes, sorted in descending order in terms of statistical significance.

\section{Discussion}

Lately, there is an increasing interest for exploring the tumor preventive actions of mastic gum and its essential oil, a natural blend of bioactive terpenes. Results obtained to date support that mastic gum/oil can inhibit the growth of several cancer types in vitro [13-16]. In addition, the anti-tumor potential of mastic oil has been recently confirmed in vivo on the experimental growth of Lewis lung adenocarcinoma (LLC) tumors, an aggressive type of mouse lung cancer and some of the underlying mechanisms have been investigated [17]. In the present study, through a genome-wide transcriptomic approach we identified for the first time the dynamic alterations occurring in gene expression of LLC cells in response to mastic oil treatment at different incubation periods $(3,6,12,24$ and $48 \mathrm{~h}$ ) and undertook a detailed analysis of the involved mechanisms using bioinformatic methodologies. Furthermore, we followed by RT-PCR the expression

Table 2: Common TF motif families in cluster 2

\begin{tabular}{llc}
\hline Family & p-value & \% TF site containing promoters \\
\hline V\$CTCF & $2.0652 \times 10^{-8}$ & $80 \%$ \\
V\$EGRF & $2.0837 \times 10^{-8}$ & $85 \%$ \\
V \$ZBPF & $3.3390 \times 10^{-8}$ & $80 \%$ \\
V\$AHRR & $8.5552 \times 10^{-8}$ & $69 \%$ \\
V\$MAZF & $2.0443 \times 10^{-6}$ & $73 \%$ \\
V\$SPIF & $7.3263 \times 10^{-6}$ & $85 \%$ \\
V\$E2FF & $1.6909 \times 10^{-4}$ & $80 \%$ \\
V\$EBOX & $3.7640 \times 10^{-3}$ & $69 \%$ \\
\hline
\end{tabular}

Common statistically significant TF motif families found in proximal promoter sequences of genes contained in cluster 2 , which are present in both mouse and human genomes. The column family refers to families of functionally similar motifs grouped together. The $p$-value is the probability to obtain a greater or equal number of sequences with a match in a random sample of the same size as the input sequence set. The percentage column depicts the percentage of genes in cluster 2 whose promoters have at least one match with the respective motif family. In each family identifier, V\$ stands for "Vertebrates". Percentages and p-value calculations are based on mouse promoters. of four selected genes, namely Pten, Hmox1, E2f7 and Nod1 in LLC as well as in other cancer cell lines of human origin, in order to reveal potential common patterns of response to mastic oil among different tumor types.

Microarray data normalization by two different algorithms provided a list of 925 genes with a significantly modified expression in mastic oil treated cells compared to untreated controls. RT-PCR selectively applied on the above mentioned genes due to their particular interest, further confirmed the expression profiles found by the microarray approach. Meta-analysis performed on the complete set of differentially expressed genes using the GO database (Table 1), comprised a statistically strong cohesive net of functions as derived from the GO tree, thus further supporting the reliability of the adopted fold change expression thresholds. This analysis demonstrated that mastic oil influences significantly a number of fundamental cellular processes such as those related to cell cycle, apoptosis, signal transduction and regulation of transcription. Also some more specific functions (e.g. glutathione transferase activity and metabolism), linked to detoxification of endogenous or exogenous metabolites, a well-known mechanism of cancer chemoprevention by several phytochemicals, including terpenoids [36-38], are affected.

It is worth mentioning that alterations in GO categories related to "negative regulation of cell proliferation", "cell cycle", "positive regulation of I- $\kappa$ B kinase/NF- $\kappa$ B cascade" and "induction of apoptosis" correlated very well with existing experimental evidence supporting that mastic oil causes regression of tumor growth by inhibiting cancer cell proliferation and survival $[13,16,17]$, reducing tumorassociated expression of inflammatory mediators [17] and down-regulating NF- $\mathrm{KB}$ transcriptional activity $[14,17]$.

An interesting result of our analysis was that among the targeted by mastic oil genes corresponding to the GO categories presented in Figure 2, Pten appeared to be relevant to three of them. Its expression was further assessed by RTPCR and found to be late up-regulated in LLC, HCT116 and K562 cells. This gene which encodes for PTEN, a dualspecificity phosphatase, has lately gained much attention as a tumor-suppressor due to its prominent inhibitory role in cancer expansion and metastasis $[33,34]$. Although little is known about the upstream regulatory pathways for PTEN, one of its most recognized down-stream actions is the blockade of PI3K/AKT signaling through de-phosphorylation of phosphatidylinositol $(3,4,5)$ tri-phosphate (PIP3) which is generated by PI3K to mediate AKT activation $[31,36]$. Active AKT then phosphorylates a plethora of targets to activate cell cycle, prevent apoptosis and trigger NF- $\mathrm{B}$ signaling [37]. Furthermore PTEN has been 
shown to antagonize tumor necrosis factor (TNF)-stimulated NF-кB-dependent gene expression, thus sensitizing cells to TNF-induced apoptosis [29]. Thereby the induction of Pten expression by mastic oil may be considered as an essential upstream effect accounting for the anti-proliferative, pro-apoptotic and anti-inflammatory actions of mastic oil through blockade of AKT and NF-kB transcriptional activity. In line with this, we found that pharmacological blockade of PTEN by bpV(phen) partially reversed the anti-tumor growth effects of mastic oil in K562 cells. These results indicate the active involvement of PTEN but also of other target pathways in tumor growth suppression by mastic oil. Compatible to this hypothesis, perillyl alcohol (one of the best studied mastic oil components) and mastic gum have been shown able to reduce the levels of phosphorylated (active) AKT [14,38] and in addition mastic oil to down-regulate the constitutive and TNF- $\alpha$ induced NF-אB-dependent gene transcription [17].

In conformity with a negative regulation of cell proliferation and/or survival by mastic oil was also the observed up-regulation of two other genes, namely E2f7 and Hrasls3. The expression of E2f7 was also determined by RT-PCR and found to be induced in LLC, HCT116 and K562 cells. E2F7 is a transcription factor which, in contrast to the other members of E2F family, has been shown to act as a repressor of several genes known to promote tumor cell proliferation [39]. Concerning Hrasls3, a member of the HREV107 type II tumor suppressors, it has been shown to exert anti-proliferative and pro-apoptotic actions and to be down-regulated by Ras-dependent signaling [40-42]. In correlation, mastic oil has been shown able to reduce Ras levels in LLC cells in vivo and in vitro [17], probably as an indirect consequence of mevalonate pathway blockade by its isoprenoid components [8], leading to disruption of Ras signaling. Furthermore, although Nod1 was found to be repressed in LLC, it was elevated in HCT116 and K562 cells indicating an heterogeneity in response to mastic oil.

Moreover, transient up-regulation of Hmox1 in all tested cell lines corroborates with the inhibitory effects of mastic oil on tumor-related inflammatory response [17]. This gene has been reported to be highly inducible by a variety of stress stimuli (hypoxia, inflammation, heavy metals, UV radiations) including several phytochemicals [43]. HMOX1, a heme-degrading enzyme, has been shown to exert anti-oxidative as well as a broad range of antiinflammatory activities attributed to inhibition of proinflammatory mediators and negative regulation of NF- $\mathrm{KB}$ signaling $[43,44]$. Besides, HMOX1 is known to be involved in the process of xenobiotic metabolism by inactivating chemically reactive metabolites and scavenging reactive oxygen species [45]. This finding along with the proposed by GO analysis modification of glutathione transferase activity (Table 1) support that activation of detoxifying enzymes might also contribute to cancer chemoprevention by mastic oil in agreement with previous studies indicating the anti-oxidative potential of mastic oil $[11,46]$. In contrast, Doi et al [47], using a mediumterm carcinogenesis assay in rat liver, have shown that Hmox1 was one of the most repressed genes after treatment with mastic oil. In our system however over-expression of Hmox 1 was observed as an early response to mastic oil treatment, while in [47] gene expression profile was determined after administration of mastic oil for 6 weeks. In addition, Doi et al reported the formation of prenoeoplastic lesions in rat liver after treatment with mastic oil which is not in accordance with our results. It is possible that the unique features of each experimental system, the intrinsic differences of each cell type and/or the presence of some distinct components in mastic gum compared to mastic oil, account for such contradictory effects. For instance Paraschos et al [48] recently reported that a polymer present in mastic gum could hinder its anti-bacterial activity and reduce the bioavailability of bioactive components. In any case, those controversial results support the need of further studies in order to investigate mastic oil metabolism and bioavailability and specify safe dosage limits.

Finally, by applying k-means clustering the complete set of genes was organized in eight clusters each representing a specific gene expression profile, probably indicating a common regulatory transcriptional mechanism (Figure 5 ). To test this hypothesis, we performed a representative promoter analysis looking for putative common cis-elements in genes grouped in cluster 2 (Table 2). Putative elements belonging to the EGR family were identified in $85 \%$ of the promoters of cluster 2 genes. Functional EGR binding sites have been identified in the promoters of several tumor suppressor genes, including Pten $[49,50]$. In particular, EGR1 has been shown to directly transactivate Pten. Furthermore, elements of the AHRR family, containing the Xenobiotic Response Element (XRE) and closely related TF binding sites involved in transcriptional stimulation of several xenobiotic metabolizing enzymes by several phytochemicals $[51,52]$, were identified in $69 \%$ of cluster 2 genes.

\section{Conclusions}

Overall, this study, by combining microarray gene expression profiling with bioinformatic analyses on a model of mouse lung adenocarcinoma provided novel evidence for the target molecules and pathways underlying mastic oil inhibitory actions on tumor cell growth and survival. Figure 6 shows a proposed mechanism of action including several key molecules involved in cell proliferation, apoptosis and inflammation based on our microarray study on mastic oil treated LLC cells and the relevant literature. 


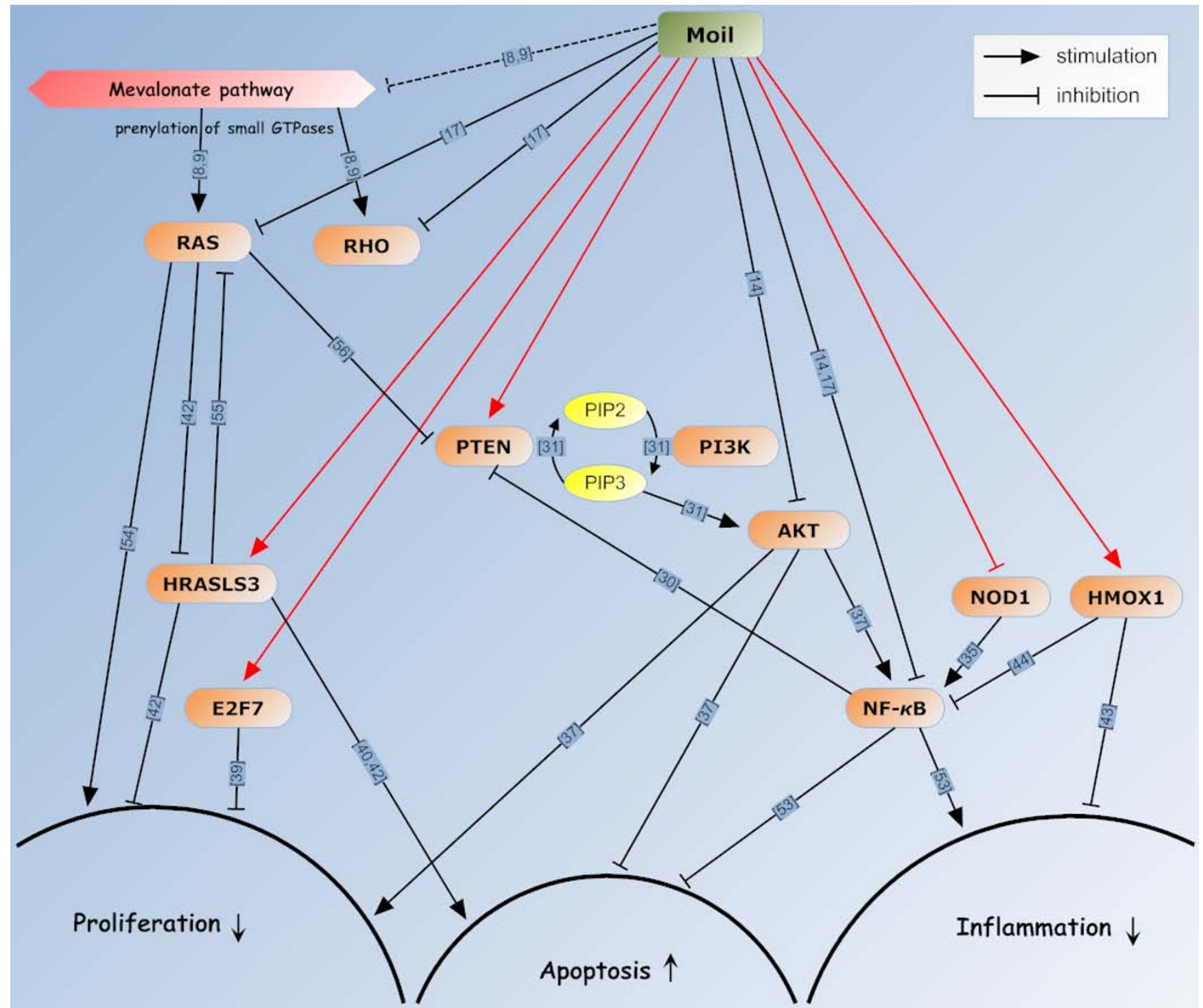

Figure 6

Model of mastic oil action mechanisms in LLC cells. Schematic representation of target molecules and pathways underlying mastic oil-mediated chemopreventive effects on tumor cell proliferation, apoptosis and inflammation based on available literature (black arrows) and evidence as derived from the present study for LLC cells (red arrows). Dashed line indicates prediction of activity based on experimental evidence from mastic oil components. Numbers on arrows correspond to respective references indicated in the text and also interactions described in references [53-56].

\section{Abbreviations}

AHRR: aryl-hydrocarbon receptor related factors; $\mathrm{bpV}(\mathrm{phen})$ : potassium bisperoxo (1,10-phenanthroline) oxovanadate; Casp4: caspase 4; Cdc45l: cell division cycle 45-like; Cks1b: CDC28 protein kinase 1b; CTCF: CCCTCbinding factor; EGRF: early growth response related factors; FDR: False Discovery Rate; GO: Gene Ontology; Hmox1: heme oxygenase 1; Hrasls3: Hras-like suppressor 3; MAZF: MYC-associated zinc fingers; NF-kB: nuclear factor kappa beta; Nod1: nucleotide-binding oligomeriza- tion domain containing 1; Pax6: paired box gene 6; Pin1: protein (peptidyl-prolyl cis/trans isomerase) NIMA-interacting 1; Ppp1cb: protein phosphatase 1, catalytic subunit, beta isoform; Pten: phosphatase and tensin homolog deleted on chromosome ten; Rnf8: ring finger protein 8; SP1F: Specificity protein 1 related factors; Stradb: STE20related kinase adaptor beta; TF: Transcription factor; ZBPF: zing binding protein factors. Throughout the text, gene names are written using Sentence case italic letters and protein names are written using CAPITAL letters. 


\section{Competing interests}

The authors declare that they have no competing interests.

\section{Authors' contributions}

PM contributed to computational analyses and metaanalyses and draft writing. OP performed the biological experiments, computational promoter analysis and draft writing. AC participated in the supervision of the computational analyses and meta-analyses. HL contributed to the conception and design of the study, supervision of biological experiments, data interpretation and manuscript writing. CR participated in the design of the study and manuscript revision. FNK participated in the study design and supervised the overall process. All authors have read and approved the final manuscript.

\section{Additional material}

\section{Additional file 1}

List of 925 differentially expressed genes in response to mastic oil. The list of 925 differentially expressed genes and their cluster memberships as derived after statistical and clustering analysis as described in Methods. Several annotation elements such as GenBank accession numbers and RefSeq IDs are included together with fold change ratios for each differentially expressed gene.

Click here for file

[http://www.biomedcentral.com/content/supplementary/17558794-2-68-S1.XLS]

\section{Acknowledgements}

This work was financially supported by the General Secretariat of Research and Development in the frame of the Program for the Evaluation of the National Research Centres (Excellence: Contract No: 20055E0 I33008I)

\section{References}

I. Jemal A, Murray T, Ward E, Samuels A, Tiwari RC, Ghafoor A, Feuer E], Thun M]: Cancer statistics, 2005. CA Cancer J Clin 2005, 55(I): 10-30.

2. American Institute for Cancer Research, World Cancer Research Fund: Food, nutrition, physical activity and the prevention of cancer: a global perspective: a project of World Cancer Research Fund International. Washington, D.C.: American Institute for Cancer Research; 2007.

3. Gopalakrishnan A, Tony Kong AN: Anticarcinogenesis by dietary phytochemicals: cytoprotection by Nrf2 in normal cells and cytotoxicity by modulation of transcription factors NFkappa B and AP-I in abnormal cancer cells. Food Chem Toxicol 2008, 46(4): I 257-1270.

4. Surh Y]: Cancer chemoprevention with dietary phytochemicals. Nature reviews 2003, 3(10):768-780.

5. de Kok TM, van Breda SG, Manson MM: Mechanisms of combined action of different chemopreventive dietary compounds: a review. Eur J Nutr 2008, 47(Suppl 2):5I-59.

6. Koutsoudaki C, Krsek M, Rodger A: Chemical composition and antibacterial activity of the essential oil and the gum of Pistacia lentiscus Var. chia. I Agric Food Chem 2005, 53(20):768|-7685.

7. Magiatis P, Melliou E, Skaltsounis AL, Chinou IB, Mitaku S: Chemical composition and antimicrobial activity of the essential oils of Pistacia lentiscus var. chia. Planta Med 1999, 65(8):749-752.

8. Mo H, Elson CE: Studies of the isoprenoid-mediated inhibition of mevalonate synthesis applied to cancer chemotherapy and chemoprevention. Exp Biol Med (Maywood) 2004, 229(7):567-585.

9. Crowell PL: Prevention and therapy of cancer by dietary monoterpenes. J Nutr 1999, I 29(3):775S-778S.

10. Kaliora AC, Stathopoulou MG, Triantafillidis JK, Dedoussis GV, Andrikopoulos NK: Alterations in the function of circulating mononuclear cells derived from patients with Crohn's disease treated with mastic. World J Gastroenterol 2007, 13(45):603|-6036.

II. Dedoussis GV, Kaliora AC, Psarras S, Chiou A, Mylona A, Papadopoulos NG, Andrikopoulos NK: Antiatherogenic effect of Pistacia lentiscus via GSH restoration and downregulation of CD36 mRNA expression. Atherosclerosis 2004, 174(2):293-303.

12. Kang JS, Wanibuchi H, Salim El, Kinoshita A, Fukushima S: Evaluation of the toxicity of mastic gum with 13 weeks dietary administration to $\mathbf{F 3 4 4}$ rats. Food Chem Toxicol 2007, 45(3):494-50I.

13. Balan KV, Prince J, Han Z, Dimas K, Cladaras M, Wyche JH, Sitaras NM, Pantazis P: Antiproliferative activity and induction of apoptosis in human colon cancer cells treated in vitro with constituents of a product derived from Pistacia lentiscus $L$. var. chia. Phytomedicine 2007, I4(4):263-272

14. He ML, Li A, Xu CS, Wang SL, Zhang MJ, Gu H, Yang YQ, Tao HH: Mechanisms of antiprostate cancer by gum mastic: NF-kappaB signal as target. Acta Pharmacol Sin 2007, 28(3):446-452.

15. He ML, Yuan HQ, jiang AL, Gong AY, Chen WW, Zhang PJ, Young $C Y$, Zhang JY: Gum mastic inhibits the expression and function of the androgen receptor in prostate cancer cells. Cancer 2006, 106( I 2):2547-2555

16. Loutrari H, Magkouta S, Pyriochou A, Koika V, Kolisis FN, Papapetropoulos A, Roussos C: Mastic oil from Pistacia lentiscus var. chia inhibits growth and survival of human $\mathrm{K562}$ leukemia cells and attenuates angiogenesis. Nutr Cancer 2006, 55(I):86-93.

17. Magkouta S, Stathopoulos G, Psallidas I, Papapetropoulos A, Kolisis F, Roussos C, Loutrari H: Protective effects of mastic oil from Pistacia lentiscus variation chia against experimental growth of Lewis Lung Carcinoma. Nutrition and Cancer: An International Journal 2009, 6 I (5):640-648.

18. Lai JP, Dalton JT, Knoell DL: Phosphatase and tensin homologue deleted on chromosome ten (PTEN) as a molecular target in lung epithelial wound repair. $\mathrm{Br} J$ Pharmacol 2007, I 52(8): I I 72-I I84.

19. Bolstad BM, Irizarry RA, Astrand M, Speed TP: A comparison of normalization methods for high density oligonucleotide array data based on variance and bias. Bioinformatics (Oxford, England) 2003, 19(2): 185-193.

20. Tzouvelekis A, Harokopos V, Paparountas T, Oikonomou N, Chatziioannou A, Vilaras G, Tsiambas E, Karameris A, Bouros D, Aidinis V: Comparative expression profiling in pulmonary fibrosis suggests a role of hypoxia-inducible factor-lalpha in disease pathogenesis. Am J Respir Crit Care Med 2007, I 76 (I I): I I08-I I I 9.

21. Storey JD, Tibshirani R: Statistical significance for genomewide studies. Proceedings of the National Academy of Sciences of the United States of America 2003, I 00( I6):9440-9445.

22. The RankGO homepage [http://www.eie.gr/nhrf/institutes/ibrb/ programmes/metabolicengineering-softwaretools.html]

23. Kossinets G, Watts DJ: Empirical Analysis of an Evolving Social Network. Science 2006, 3 I I (88):88-90.

24. Efron B, Tibshirani R: An introduction to the bootstrap. New York: Chapman \& Hall; 1993.

25. Tibshirani R, Walther G, Hastie T: Estimating the number of clusters in a data set via the gap statistic. J R Statist Soc 200I, 63(2):4II-423.

26. Xuan Z, Zhao F, Wang J, Chen G, Zhang MQ: Genome-wide promoter extraction and analysis in human, mouse, and rat. Genome Biol 2005, 6(8):R72.

27. The Genomatix webpage [http://www.genomatix.de]

28. Cartharius K, Frech K, Grote K, Klocke B, Haltmeier M, Klingenhoff $A$, Frisch M, Bayerlein M, Werner T: MatInspector and beyond: promoter analysis based on transcription factor binding sites. Bioinformatics 2005, 2 I (13):2933-2942.

29. Mayo MW, Madrid LV, Westerheide SD, Jones DR, Yuan XJ, Baldwin AS Jr, Whang YE: PTEN blocks tumor necrosis factor-induced NF-kappa B-dependent transcription by inhibiting the transactivation potential of the $\mathbf{p} 65$ subunit. J Biol Chem 2002, 277(I3): IIII6-III25 
30. Vasudevan KM, Gurumurthy S, Rangnekar VM: Suppression of PTEN expression by NF-kappa B prevents apoptosis. Molecular and cellular biology 2004, 24(3): I007-102I.

31. Song G, Ouyang G, Bao S: The activation of Akt/PKB signaling pathway and cell survival. J Cell Mol Med 2005, 9(I):59-71.

32. Markovic J, Mora NJ, Broseta AM, Gimeno A, de-la-Concepcion N, Vina J, Pallardo FV: The depletion of nuclear glutathione impairs cell proliferation in $3 \mathrm{t} \mathbf{3}$ fibroblasts. PLOS One 2009, 4(7):e64|3.

33. Baker S): PTEN enters the nuclear age. Cell 2007, I 28(I):25-28.

34. Salmena L, Carracedo A, Pandolfi PP: Tenets of PTEN tumor suppression. Cell 2008, I33(3):403-4|4.

35. Shaw MH, Reimer T, Kim YG, Nunez G: NOD-like receptors (NLRs): bona fide intracellular microbial sensors. Curr Opin Immunol 2008, 20(4):377-382.

36. Simpson L, Parsons R: PTEN: life as a tumor suppressor. Exp Cell Res 200I, 264(I):29-4I.

37. Manning BD, Cantley LC: AKT/PKB signaling: navigating downstream. Cell 2007, I 29(7): | 26|-1274.

38. Loutrari H, Hatziapostolou M, Skouridou V, Papadimitriou E, Roussos C, Kolisis FN, Papapetropoulos A: Perillyl alcohol is an angiogenesis inhibitor. J Pharmacol Exp Ther 2004, 3 I I (2):568-575.

39. de Bruin A, Maiti B, Jakoi L, Timmers C, Buerki R, Leone G: Identification and characterization of E2F7, a novel mammalian E2F family member capable of blocking cellular proliferation. Biol Chem 2003, 278(43):4204I-42049.

40. Nazarenko I, Schafer R, Sers C: Mechanisms of the HRSL3 tumor suppressor function in ovarian carcinoma cells. I Cell Sci 2007 , | 20(Pt 8): | 393-| 404

4I. Sers C, Emmenegger U, Husmann K, Bucher K, Andres AC, Schafer $R$ : Growth-inhibitory activity and downregulation of the class II tumor-suppressor gene H-revl07 in tumor cell lines and experimental tumors. J Cell Biol 1997, I36(4):935-944.

42. Sers C, Husmann K, Nazarenko I, Reich S, Wiechen K, Zhumabayeva B, Adhikari P, Schroder K, Gontarewicz A, Schafer R: The class II tumour suppressor gene H-REVI07-I is a target of interferon-regulatory factor-I and is involved in IFNgammainduced cell death in human ovarian carcinoma cells. Oncogene 2002, 2 I ( I 8):2829-2839.

43. Prawan A, Kundu JK, Surh YJ: Molecular basis of heme oxygenase-I induction: implications for chemoprevention and chemoprotection. Antioxid Redox Signal 2005, 7( I I- / 2): 1688-1703.

44. Oh GS, Pae HO, Lee BS, Kim BN, Kim JM, Kim HR, Jeon SB, Jeon WK, Chae HJ, Chung HT: Hydrogen sulfide inhibits nitric oxide production and nuclear factor-kappaB via heme oxygenaseexpression in RAW264.7 macrophages stimulated with lipopolysaccharide. Free Radic Biol Med 2006, 4I(I): I06-II 9.

45. Giudice A, Montella M: Activation of the Nrf2-ARE signaling pathway: a promising strategy in cancer prevention. Bioessays 2006, 28(2): |69-|8|.

46. Sakagami H, Kishino K, Kobayashi M, Hashimoto K, lida S, Shimetani A, Nakamura Y, Takahashi K, Ikarashi T, Fukamachi H, et al.: Selective antibacterial and apoptosis-modulating activities of mastic. In Vivo 2009, 23(2):215-223.

47. Doi K, Wei M, Kitano M, Uematsu N, Inoue $M$, Wanibuchi $H$ : Enhancement of preneoplastic lesion yield by Chios Mastic Gum in a rat liver medium-term carcinogenesis bioassay. Toxicol Appl Pharmacol 2009, 234(I): 135-142.

48. Paraschos S, Magiatis P, Mitakou S, Petraki K, Kalliaropoulos A Maragkoudakis $P$, Mentis A, Sgouras D, Skaltsounis AL: In vitro and in vivo activities of Chios mastic gum extracts and constituents against Helicobacter pylori. Antimicrob Agents Chemother 2007, 5 I (2):55I-559.

49. Baron V, Adamson ED, Calogero A, Ragona G, Mercola D: The transcription factor Egr I is a direct regulator of multiple tumor suppressors including TGFbeta I, PTEN, p53, and fibronectin. Cancer Gene Ther 2006, I3(2): I I5-I24.

50. Virolle T, Adamson ED, Baron V, Birle D, Mercola D, Mustelin T, de Belle I: The Egr-I transcription factor directly activates PTEN during irradiation-induced signalling. Nat Cell Biol 200I, 3(12): I I I24-| | 28.

5I. Li L, Stanton JD, Tolson AH, Luo Y, Wang H: Bioactive terpenoids and flavonoids from Ginkgo biloba extract induce the expression of hepatic drug-metabolizing enzymes through pregnane $X$ receptor, constitutive androstane receptor, and aryl hydrocarbon receptor-mediated pathways. Pharm Res 2009, 26(4):872-882.

52. Kohle C, Bock KW: Activation of coupled Ah receptor and Nrf2 gene batteries by dietary phytochemicals in relation to chemoprevention. Biochem Pharmacol 2006, 72(7):795-805.

53. Karin M: Nuclear factor-kappaB in cancer development and progression. Nature 2006, 44 I (7092):43I-436.

54. Rajalingam K, Schreck R, Rapp UR, Albert S: Ras oncogenes and their downstream targets. Biochimica et biophysica acta 2007, I773(8): I I77-I I 95.

55. Tsai FM, Shyu RY, Jiang SY: RIG I inhibits the Ras/mitogen-activated protein kinase pathway by suppressing the activation of Ras. Cell Signal 2006, I 8(3):349-358.

56. Vasudevan KM, Burikhanov R, Goswami A, Rangnekar VM: Suppression of PTEN expression is essential for antiapoptosis and cellular transformation by oncogenic Ras. Cancer Res 2007, 67(2I): $10343-10350$

\section{Pre-publication history}

The pre-publication history for this paper can be accessed here:

http://www.biomedcentral.com/1755-8794/2/68/prepub
Publish with Biomed Central and every scientist can read your work free of charge

"BioMed Central will be the most significant development for disseminating the results of biomedical research in our lifetime. "

Sir Paul Nurse, Cancer Research UK

Your research papers will be:

- available free of charge to the entire biomedical community

- peer reviewed and published immediately upon acceptance

- cited in PubMed and archived on PubMed Central

- yours - you keep the copyright 